La literatura intercultural o de migración no ocupa un lugar protagonista en el mercado editorial español. Desde la investigación filológica se ha abordado en diversas ocasiones la recepción de la literatura alemana en España desde un punto de vista general, pero no se ha analizado ese mismo fenómeno respecto a la obra de los autores con ascendencia migratoria y que redactan su obra en alemán. En esta encrucijada en que se coloca la denominada literatura intercultural, resulta pertinente añadir la visión que aporta la traducción a una tercera lengua (en este caso el español) de estas obras surgidas de la pluma de emigrantes o descendientes de emigrantes y que ya suponen todo un nicho de mercado en el mundo editorial germanófono.

Se pretende en esta contribución exponer el estado actual del mercado editorial español en relación con la literatura de migración escrita en alemán, aportar datos estadísticos y explorar las causas sobre las que estos se sustentan.

PALABRAS CLAVE: traducción, literatura de migración en alemán, literatura intercultural, alemán, español.

\title{
La literatura de migración en lengua alemana traducida al español (I950-20I8)
}

\section{German intercultural literature translated into Spanish}

Intercultural or migration literature does not play a leading role in the Spanish publishing market. Philological research has often approached the reception of German literature in Spain from a general perspective, but works written in German by authors with a migrant background have not been studied nor analysed in the same way yet. In this crossroads where the so-called intercultural literature is to be found, it seems necessary to add the complementary approach provided by the translation of the works written by migrants or by migrants' descendants into a third language (in this case, Spanish), since they have become are a real niche market in the German-speaking publishing world. In this paper we aim at stating the standpoint of the Spanish publishing market regarding intercultural literature written in German, displaying statistics and exploring the causes that lie behind.

KEY WORDS: translation, German migration literature, intercultural literature, German, Spanish. 


\section{INTRODUCCIÓN}

La literatura intercultural o de migración escrita en lengua alemana ha sido estudiada y analizada desde el ámbito de la filología y la crítica literaria en numerosas ocasiones (Pazarkaya, I984; Kreuzer, I984; Weinrich, I984; Chiellino, 2000; Durzak y Kuruyazic, 2004; Schenk et al., 2004; Bürger-Koftis, 2008; Amodeo et al., 2009; Kamm et al., 2010; Cornejo et al., 20I4; Pereyra, 2016, entre otros), si bien no parece habérsele dedicado tanta atención a la visión adicional que aporta la traducción a obras que ya de por sí son en sí mismas una suerte de traducción sentimental, de una lengua y cultura originales a una lengua y cultura no verdaderamente ajenas, pero en la que las obras de migrantes se perciben aún como algo ajeno y exótico (salvo el caso de algunos trabajos aislados, como los de Valero Cuadra, 2010 o Feld, 2010). En este contexto parece entonces adecuado añadir a la ecuación ese tercer movimiento migratorio que supone la traducción a una tercera lengua (el español en el caso que nos ocupa) de estas obras surgidas de la pluma de emigrantes o descendientes de emigrantes, que ya suponen todo un nicho de mercado en el mundo editorial germanófono. En la tarea de traslación, el traductor deja de ser un mero prestador de servicios para convertirse en verdadero cocreador de una dinámica social (Feld, 2010: 443).

\section{Definición de literatura de migración}

En alemán, el concepto de literatura intercultural o literatura de migración goza de tantas denominaciones como investigadores se han ocupado de ella: Ausländerliteratur, Brückenliteratur, Gastarbeiterliteratur, Migrantenliteratur, Migrationsliteratur, interkulturelle Literatur, multikulturelle Literatur, Exilliteratur, Secondos/ Secondo Literatur, transnationale Literatur, Lite- ratur nationaler Minderheiten, incluso kosmopolitische Räume (Spoerri, 2010) (vid. también Kreuzer, I984, Esselborn, 2004; Mecklenburg, 2004; Rosell, 2007; Thore, 2004; Weinberg, 20I4 o Pereyra, 2or6, entre otros). Si nos atenemos a la definición del clásico diccionario Metzler Lexikon Literatur (Burdorf et al., 2007: 498), se entiende por este tipo de literatura la compuesta por textos de autores de procedencia cultural y lingüística distinta a la alemana pero que escriben en alemán y publican en el contexto germanófono, si bien se apuntan igualmente otros criterios de aún mayor trascendencia, como las experiencias pluriculturales y multilingües que se dan en situaciones de minoría y que aportan nuevos puntos de vista a la literatura en lengua alemana, así como la decisión consciente de abandonar la lengua materna en favor del alemán para la creación literaria. En ocasiones se ha criticado que se haga uso de la lógica del mercado para establecer límites dentro la investigación filológica, y se han planteado cuestiones como las siguientes:

Mit welchem Recht sprechen wir eigentlich von ,Migrantenliteratur', wenn noch gar nicht genügend Studien vorliegen, die die so versammelten Texte einfach als Texte und eben nicht vom Leben ihrer VerfasserInnen her lesen? Was soll man zur vermeintlichen Einheit dieses Gernes sagen, wenn diese bisher immer nur von einem extratextuallen Kriterium abgeleitet wurde? (Weinberg, 20I4: I6-I7).

Se censura por lo tanto el hecho de emplear un criterio extratextual como es la procedencia geográfica o familiar del autor para su adscripción a un grupo, el de Migrantenliteratur, cuya misma existencia se pone en entredicho. En similares términos se expresa Spoerri (2008: 200) en relación con los autores procedentes de la Europa del Este y que publican en Suiza, pero añade: 
Von Belang sind die biografischen Voraussetzungen der Schriftstellerinnen und Schriftsteller insofern auch für Literatur, als sie das Verhältnis zur Sprache, in der die Autoren schreiben, prägen. Ein weiterer wichtiger Punkt sind die thematischen und motivischen Spuren, die bei vielen, aber längst nicht bei allen dieser Autorinnen und Autoren die literarischen Texte beeinflussen. Will man zudem über die Literatur von Migranten und deren Kinder sprechen, muss man immer auch den Umgang der Wissenschaft und der Öffentlichkeit mit ihr erörtern, die Vorzeichen, unter denen diese Literatur thematisiert und untersucht wird, transparent machen.

Abunda Spoerri en los condicionantes extratextuales que tienen que ver con las circunstancias vitales de los escritores, pero apunta también en la dirección de la relación que tienen con la lengua en la que escriben y en los temas que por lo general aborda una buena parte del colectivo.

Resulta obvio que el fenómeno es tremendamente complejo, pero baste una definición como esta para acotar los límites de este estudio: «Migrationsliteratur [wird verstanden] als eine historische und prozessuale Variable [...], als eine Form der kommunikativen literarischen Praxis, die ihre Legitimation sowohl aus der erfahrungsgesättigten Erzählerperspektive als auch aus der imaginativen Fremdenschau schöpfen kann» (Cornejo et al., 20I4: II), es decir, como un tipo de literatura que se ve impregnada tanto por la propia experiencia vital de sus autores como por la visión construida y estereotipada de lo exótico, lo ajeno.

Hay que tener en cuenta que hoy en día, en Alemania, viven en torno a ig millones de habitantes que poseen el conocido Migrationsbintergrund (o bien son migrantes o hijos de al menos un progenitor que no tenía nacionalidad alemana al nacer), es decir, aproximadamente un $23 \%$ de la población alemana es de origen migratorio, un porcentaje que aumenta considerablemente en las grandes ciudades. ${ }^{\mathbf{I}}$ No obstante, y a pesar de que los autores de este heterogéneo y poco definido grupo ${ }^{2}$ escriben, publican, reciben premios (incluso premios concebidos específicamente para ellos, como se verá más abajo), presentan sus obras en ferias del libro y recorren talleres y escenarios internacionales en calidad de autores alemanes, siguen encontrando dificultades en verse reconocidos como parte integrante, claramente y sin fisuras, del canon literario alemán establecido, o quizá solo unos pocos, autores de libros de éxito y bestsellers reconocidos, como Rafik Schami o Feridun Zaimoğlu (Ruiz, 2005; Amodeo et al., 2009; Pereyra, 2016). A este respecto, no se puede obviar el punto de vista de quienes han sido englobados bajo esa denominación: el autor de origen kurdo-iraquí Sherko Fatah cree que lo que les diferencia de otros autores no es tanto la cuestión de la procedencia, sino la urgencia que hay por encontrar respuesta a la cuestión identitaria por parte de este colectivo: «Das Entscheidende an uns mit diesem 'Migrationshintergrund' ist einfach, dass sich die Frage nach der Indentität dringlicher stellt. Die Frage selbst ist universell, die hat jeder Mensch. [...] Es ist ein wenig dringlicher, weil wir damit konfrontiert werden, und das ist im Grunde der Unterschied» (Amodeo et al., 2009: 47).

I Fuente: Statistisches Bundesamt, nota de prensa del I de agosto de 20I8. Disponible en: https://www.destatis. de/DE/PresseService/Presse/Pressemitteilungen/2018/o8/ PDi8_282_I25Ir.html [consulta: I3-XI-20I8].

2 La misma noción de 'minoría' es compleja de definir, como apunta Mecklenburg (2004: 24), no sin cierta ironía: «Schon der Basisbegriff Minderheit' ist gar nicht so leicht zu fixieren. [...] Viele Schriftsteller betonen mehr ihre Differenz als die Zugehörigkeit zu einer Gruppe, zugespitzt gesagt: Autoren bilden gern Minderheiten, zu denen nur eine Person gehört, nämlich der Autor selbst». 
En el espacio que Rosell dedica a enmarcar su investigación de 2007, denuncia «nuestra enfermiza y generalizada propensión a dividir los infinitos matices de la experiencia, las creencias y el conocimiento humanos en parcelas bien delimitadas y acotadas» (Rosell, 2007: I30), y añade: «[S]i la verdadera patria está en la lengua, entonces la literatura de estos autores [emigrantes o hijos de emigrantes] es literatura alemana, o, al menos, literatura en lengua alemana - deutschsprachige Literatur - sin más» (ibidem). Rosell concluye sus reflexiones aseverando que la literatura surgida de la pluma de estos autores es ya parte de la historia alemana y que la lengua alemana se ve indefectiblemente afectada y modificada por las experiencias e historias que vienen de fuera. Hay quien apunta, de hecho, que el lugar en que se entrecruzan dos o más culturas

ein Potential für eine emanzipierte interkulturelle Verständigung innehat. In der aktuellen sozialen und politischen Praxis entsteht dieser Ort im Wesentlichen mit dem Phänomen der globalen Migration [...]. Der Translator wird also zu dem Inhaber der dritten Ebene und ist damit der verantwortliche Experte für den Erfolg bzw. Misserfolg des translatorischen Prozesses (Feld, 2010: 445-446).

De ese tercer espacio que da pie a la comprensión del otro, del fenómeno intercultural y migratorio, se hace dueño el traductor, un espacio que podría también entenderse en relación con el third space del que habla Bhabha (1994) y que supone la condición necesaria para que se articulen las diferencias culturales (Schenk et al., 2004: VIII). En este contexto es en el que se pretende explorar la traducción al español de estas obras que representan un cruce de culturas. Más adelante se dará cuenta de qué autores se han seleccionado para el presente estudio.

\section{La traducción de la literatura en lengua alemana en España}

Como se apuntaba en las líneas introductorias, ya ha habido trabajos que han abordado el fenómeno literario de la literatura alemana intercultural o de migración. Hay que citar necesariamente al traductor del alemán y académico de la RAE Miguel Sáenz, quien, en un artículo de 1995 titulado "Geschichte einer unmöglichen Liebe. Die deutsche Literatur in Spanien seit I945», trazó un conciso retrato de la recepción en España de la literatura escrita en lengua alemana de la segunda mitad del siglo xx. En relación con la literatura de migración, apuntaba Sáenz (1995: I75):

Darüber hinaus kommt es zu einem bislang unbekannten Phänomen: Autoren werden übersetzt, deren Muttersprache nicht das Deutsche ist oder die aus Ländern kommen, in denen das Deutsche Zufluchtsort von Minderheiten ist [...], und beim spanischen Publikum kommt diese Literatur mit ihren neuen Rhythmen und fremdartigen Melodien außerordentlich gut an.

No podemos saber en qué datos se fundan estas declaraciones, pero resulta interesante en todo caso la observación sobre el ritmo y la melodía de estas obras y el hecho de que Sáenz considere que este sea el motivo de su aparente éxito entre el público español.

También Cuéllar Lázaro ha estudiado las traducciones al español de obras alemanas, tanto en su obra del año 2000 Dobletes de traducción y traductología: las traducciones al castellano en España de la literatura contemporánea en lengua alemana (1945-1990) como en su artículo de 2005 «La literatura contemporánea en lengua alemana en España: 45 años de 
traducciones».3 Como conclusión principal de ambos trabajos cabe destacar que el número de traducciones en este par de lenguas ha crecido exponencialmente desde I945, como no podría ser de otro modo en el mundo globalizado y permanentemente interconectado en el que habitamos. El auge, encuentra esta autora, se da en la década de los años 8o, una década en la que se publica casi el mismo número de traducciones del alemán al español que en los 35 años anteriores (Cuéllar Lázaro, 2005: 338339). En estas investigaciones, sin embargo, la literatura de migración no está recogida como tal, y por lo tanto habrán de consultarse otras fuentes para obtener datos significativos.

Para completar la visión que han aportado otros investigadores a este fenómeno, sin duda hay que mencionar el artículo de 2013 de Isabel Hernández «¿Un amor imposible? Acerca de la traducción de literatura alemana en España durante el siglo $\mathrm{XX}$ ». La autora presenta un recorrido detallado y documentado por el mercado editorial en español en lo que se refiere a la literatura alemana. En este trabajo se encuentran aseveraciones que pueden aportar pistas sobre la recepción de textos alemanes por parte del público hispanohablante. Dice Hernández (2013: 317): «[T]raducciones de la lengua original sí las hubo en todos los tiempos, aunque no todas ellas precisamente buenas, otro de los motivos, tal vez, por el que la literatura alemana tiene para el lector medio hispanohablante ese matiz de literatura imposible, tremendamente difícil, y a la que cuesta acercarse». Y aun añade más adelante (ib.: 326):

3 En ambos trabajos la autora hace notar la dificultad que supone la búsqueda y elaboración del corpus sobre el que basar su análisis, por no contar con fuentes bibliográficas ni catalográficas completas, una crítica que hacemos propia en el presente estudio.
[L]a situación para la literatura alemana no será nunca, debido a sus dificultades de recepción, precisamente la más halagüeña, pues se ve obligada a competir con todo lo procedente de los países anglófonos, de los que se traduce veinte veces más que de los de lengua alemana. ${ }^{4}$

\section{El Libro blanco de la traducción editorial en} España (2010: 55) arroja las siguientes cifras: el $66,9 \%$ de los libros traducidos en España provienen del inglés; $43,8 \%$ lo hacen del francés y solo un $15, \mathrm{I} \%$ se vierten desde el alemán. Por su parte, del informe anual Panorámica de la edición española de libros 2017 (Ministerio de Cultura y Deporte, 20I8: 26) se extrae que del alemán, en cifras globales, se tradujo al castellano tan solo un $3,7 \%$ del total de obras traducidas, en un porcentaje que decae desde el 5,6\% que el mismo informe daba para el año 20I3. En cuanto a las obras literarias, que son las que aquí nos ocupan, dicho informe recoge únicamente el dato global de traducciones al castellano (en el último año recogido, 2017 , se publicaron 552I traducciones de obras de creación literaria en nuestro país, lo que supone un $25,4 \%$ del total de la creación literaria publicada en España [Ministerio de Cultura y Deporte, 20I8: II5]). En una consulta personal para este trabajo al Observatorio de la Lectura y el Libro se nos ofrecen los siguientes datos: en 2017 se tradujeron del alemán un total de 582 títulos, de los que 168 fueron traducciones al castellano de obras de creación literaria.

Este último dato, por bajo que pueda resultar, no debería llevar a creer que no hay lugar para la literatura escrita en lengua alemana en el mercado español. Más bien al contrario, y

4 En su artículo de 20r3 Hernández aporta este dato, mientras que, por su parte, casi diez años antes Dreymüller apuntaba que en España se traduce quince veces más del inglés que del alemán (Dreymüller, 2004: 6I). 
como apunta de nuevo Hernández, existe un "público claramente intelectual, conocedor sobrado del pensamiento y de las grandes manifestaciones literarias alemanas» (2013: 3I8), y quizá es a ese público al que se dirigen las traducciones que a continuación se expondrán. O, quizá, a una nueva generación de lectores hispanohablantes hijos a su vez del fenómeno migratorio, como apuntaba Valero Cuadra (2010: 309): «[P]ero es un fenómeno que aún no existe propiamente dicho en España, aunque llegará a nuestras letras en cuanto comience a editarse la obra escrita por el ya numeroso grupo de emigrantes que reside entre nosotros, y sus descendientes».

De la incomprensión que apuntaba Hernández del lector español hacia lo que llega de Alemania también se hace eco Saalbach (I995) con la siguiente afirmación: "Auf den ersten Blick sieht es so aus, als könnte ein spanischer Leser Texte der beschriebenen Art ohne weiteres überhaupt nicht richtig verstehen» (I995: 527), pero se desdice más adelante al sostener que la recepción en España de la literatura alemana contemporánea tiene éxito, o puede tenerlo, al existir paralelismos y conexiones con la realidad española, ni tan ajena ni distinta a la alemana. Sí es cierto que el traductor literario es, por principio, un lector, $y$, como tal, un individuo que recibe y por lo tanto reproduce los textos bajo unas circunstancias siempre individuales y siempre marcadas por su universo particular (Fortea, 2009: 7); en el caso de la literatura de migración, además, se ve «in vielfältige Verflechtungen von asymmetrischen interkulturellen Machtverhältnissen und kulturell bedingten zwischenmenschlichen Konflikten eingebunden, bei denen er sich - oft unbewusst - positioniert» (Feld, 2010: 444).

Poniendo, pues, el foco estrictamente en la literatura de migración o literatura intercultural en lengua alemana, Valero Cuadra realiza un recorrido por las obras traducidas al español escritas «por autores de origen inmigrante afincados en la República Federal Alemana» en un artículo de 20I0, en cuyas conclusiones recoge dos aspectos interesantes: se detecta un incremento de las traducciones de estas obras a partir del año r992 y, según la autora, se trata de una literatura en gran medida «aún desconocida en España» (Valero Cuadra, 2010: 309).5

Por su parte, las reflexiones de la crítica literaria y traductora Dreymüller (2004) apuntan a que la literatura en lengua alemana está bien representada en el panorama editorial español y que los lectores hispanohablantes han podido ser testigos en lengua castellana del desarrollo literario alemán en la década 1994 a 2004. Sin embargo, en la conclusión de su trabajo, Dreymüller alude a un problema no expuesto hasta el momento y que afecta a toda la producción editorial, no solamente a las traducciones: el carácter efímero de las nuevas publicaciones. Con el trepidante ritmo de publicación y el afán editorial de mantener permanentemente actualizados catálogos y estanterías, al lector no le da tiempo ni tan siquiera de hacerse una idea de las novedades ni, por supuesto, de asumirlas e integrarlas en su acervo cultural. Las condiciones económicas y de mercado que obligan a retirar una publicación reciente de las estanterías al cabo de poco más de tres semanas son, según Dreymüller, en gran medida las culpables de la actual situación de la literatura alemana en España. La autora va más allá en su trabajo de 2008 cuando denuncia la ausencia de una literatura alemana inconfundible o digna de ser tildada como tal a modo de grupo de autores que se unan en un programa literario con idio-

5 Téngase en cuenta que esta aseveración reposa sobre datos recogidos en 2009 . 
sincrasia propia (2008: 349), a pesar de tener una producción editorial como nunca antes se había visto. Y añade (2008: 350):

La mayoría de las publicaciones [...] no plasman ninguna nueva conciencia histórica, ni suponen renovación alguna, sino más bien diversas modalidades más o menos acomodaticias del incuestionado Zeitgeist oportunista [...]. Los argumentos que respaldan la presentación de un libro no son ya literarios, sino comerciales.

Sin embargo, de esta visión negativa del entorno literario alemán salen bien librados tanto los escritores provenientes de la antigua RDA como los hijos de padres emigrantes, quienes, según Dreymüller, «apuntan estéticamente más alto y se sirven de un lenguaje más rico y experimental» (2008: 35I). En similares términos se expresa en un artículo de prensa publicado con ocasión de las últimas elecciones parlamentarias en Alemania (Dreymüller, 20I7), en el que afirma que los relatos de huida y expulsión o de desplazamientos migratorios forzados son hoy en día un campo amplio y fértil en el que puede florecer una buena literatura alemana. No es la única reflexión en esta dirección. Mein por su parte asevera, no sin ironía: «die "Kanaken" sind im kulturellen Mainstream der Erlebnisgesellschaft angekommen» (2004: 20I4; el autor emplea intencionadamente el despectivo vocablo Kanaken haciendo referencia directa a la obra de 1995 de Zaimoğlu titulada Kanak Sprak. 24 Mißtöne vom Rande der Gesellschaft).

Los trabajos expuestos hasta el momento dan buena muestra del interés investigador que despierta la recepción de la literatura alemana en España. No en vano, España es uno de los países que cuenta con más licencias de traducción de obras alemanas en el extranjero. ${ }^{6}$ En las próximas líneas se procurará acotar el fenómeno a las más recientes traducciones editadas en nuestro país de obras escritas originalmente en alemán por autores de origen inmigrante.

\section{DESARROLLO DEL ESTUDIO}

Para abordar esta tarea, que sin duda merece un estudio en mayor profundidad, se ha consultado una serie de fuentes que, como reflejan Santana López et al. (20I7) en un análisis sobre la visibilidad de los traductores en los catálogos y repertorios bibliográficos españoles, están aún lejos de ser completas ni fidedignas, tanto por su irregular cobertura como por la heterogeneidad de los niveles de descripción bibliográfica que presentan. A estas dificultades cabe añadir la de acotar claramente el grupo de autores a quienes incluimos en este estudio, algo que, como ha quedado patente en las páginas precedentes, ni es sencillo ni puede responder a un único criterio de clasificación. Por todo ello, no aspiramos a ofrecer datos concluyentes, pero sí un primer acercamiento sobre el que construir en el futuro un estudio más completo.

A este respecto, hay que recordar que, si bien los márgenes de la denominada literatura intercultural no son claros, sí establecemos una línea divisoria para nuestro estudio entre la «literatura de migración» (Migrationsliteratur), creada por emigrantes o descendientes de emigrantes, y la «literatura del exilio» (Exilliteratur),

6 En 20I7, se concedieron 7856 licencias de traducción a otras lenguas, y España fue el tercer comprador de licencias a Alemania, solo por detrás de China y Turquía (Ardanuy Soldevill, 20I8: I3). En la página web del Goethe Institut se aportan los datos de las licencias de traducción de obras alemanas vendidas a España en la década 20052015 (fluctúan de las 529 del año 2005 a las 4I2 de 20I5): https://www.goethe.de/ins/es/es/kul/sup/lit/bid.html [consulta: I3-XII-2OI8]. 
limitada a los exiliados alemanes de los años 30 y 40 del pasado siglo (Esselborn, 2004: II). Esta última no tiene cabida en estas páginas. Cabe destacar, además, que se ha eliminado de la selección a los autores cuya obra no se redacta originalmente en alemán, pues es este un hecho que no los hace aptos para los fines que aquí se persiguen. Sirva como ejemplo la exclusión del africano Eze Chi Chiazo (Chiellino, 2000: 26I), pues, aunque editó un poemario en alemán en 1996, sus obras más conocidas y significativas se publicaron en inglés. $\mathrm{O}$ el caso de la turca Aysel Özakin, que recibió mucha atención en Alemania por sus obras originalmente escritas en turco y después traducidas al alemán, pero que escribe sobre todo en turco (y en menor medida en inglés), al igual que el también turco Aras Ören (primer galardonado con el premio Adelbert von Chamisso). Tampoco se ha tenido en cuenta a autores que escriben mayoritariamente poesía (como los turco-alemanes Zehra Çirac o Yüksel Pazarkaya, el iraní Cyrus Atabay, el poeta húngaro Lászki Csiba o a José F. A. Oliver, autor de origen español que escribe en ambas lenguas, entre otros): se trata, como es bien sabido, de un material literario con bajas cifras de ventas y, por lo tanto, se podría comprender la reticencia a publicar poesía desde un punto de vista económico, a lo que habría que agregar la dificultad añadida que supone traducir poesía de origen migratorio o intercultural, con todos los juegos lingüísticos e interculturales a los que se presta. Se ha eliminado asimismo a los autores cuya obra es anterior a 1950, o a quienes escriben mayoritariamente trabajos de no ficción, ensayos o resultados de investigación (como es el caso de Asfa-Wossen Asserate o el citado Chiellino).

Para seleccionar a los autores objeto de análisis, nos hemos basado en los estudios académicos consultados para este trabajo (Esselborn,
2004; Mecklenburg, 2004; Schenk et al., 2004; Dreymüller, 2004 y 2008; Rosell, 2007; BürgerKoftis, 2008; Amodeo et al., 2009; Kamm et al., 2oro; Valero Cuadra, 2oro; Hernández, 20I3; Cornejo et al., 20I4; Pereyra, 2016) y en las apreciaciones que estos expertos hacen sobre la inclusión de unos autores frente a otros bajo el paraguas de la literatura intercultural. También se ha incluido a los escritores analizados en el manual del año 2000 Interkulturelle Literatur in Deutschland - ein Handbuch (Chiellino, 2000), que, a pesar de no ser una obra actual, sigue siendo una obra de referencia sobre el asunto y recoge la panorámica de la literatura de migración alemana hasta el año de su publicación (paradójicamente queda excluido de nuestra selección el editor de este manual, Gino Carmine Chiellino, por componer sobre todo ensayos y literatura de no ficción). También se ha incluido en la selección a los galardonados con el premio Adelbert von Chamisso, que concedió la Fundación Robert Bosch en el período que va de 1985 a 2017 (el último galardón se concedió en marzo de 20I7) a autores que publicaran en alemán y «deren Werk von einem Kulturwechsel geprägt ist».7 Sobre este premio hay que decir que no se otorgaba basándose en criterios de proporcionalidad sobre los países de procedencia de los autores ni en su lugar de residencia, sino únicamente en la calidad literaria de los textos y su fuerza expresiva. Un factor

7 Información extraída de http://www.bosch-stiftung. de/de/projekt/adelbert-von-chamisso-preis-der-robertbosch-stiftung [consulta: I-XII-20I7], donde se añade: «Die Preisträger verbindet zudem ein außergewöhnlicher, die deutsche Literatur bereichernder Umgang mit Sprache». No se incluye en esta selección a los galardonados con el premio Adelbert von Chamisso denominado Förderpreis, puesto que se trataba de un premio para autores con poca trayectoria o con obra no publicada, un hecho este que no los haría aptos para ser traducidos a otra lengua y su inclusión, por lo tanto, desvirtuaría los resultados de este estudio. 
fundamental en la concesión del premio residía en la perspectiva multicultural de la obra del galardonado y en el perfil de Kulturvermittler de los premiados (Ackermann, 2008: 17 ).

Hay un buen número de autores que el lector experto echará en falta y otros que no consideraría incluir en el estudio: si atendemos únicamente a criterios extratextuales y de circunstancias vitales, sin duda se debería incluir en la selección a Herta Müller, de origen rumano pero afincada en Alemania desde los 33 años; sin embargo, que el alemán sea su lengua materna, unido al hecho de que la propia autora no se considera parte de este heterogéneo grupo, hace que resulte excluida de este estudio. ${ }^{8} \mathrm{La}$ concesión del Nobel en 2009, además, hizo que en 2010 se publicaran hasta cuatro de sus obras en castellano, y que desde entonces se traduzcan siempre sus nuevos trabajos al español, un hecho este que en cierta medida podría desvirtuar las estadísticas de este modesto estudio. También hay que añadir que Müller no solo escribe ficción, y por lo tanto este sería otro motivo su de exclusión para los fines que aquí perseguimos. Otros autores ausentes de este estudio, a pesar de formar parte del grupo al que aquí nos dedicamos, no se incluyen por no encontrarse citados ni mencionados en las obras de literatura secundaria tomadas como fuente de referencia (como, por ejemplo, Shida Bazyar).

Las fuentes de consulta empleadas han sido tanto el Index Translationum de la UNESCO ${ }^{9}$

8 Sobre la consideración de la obra de Müller en la crítica literaria alemana y su inclusión o no en el grupo de la literatura intercultural, vid. Bozzi, 2005, en especial pp. I4-24.

9 Esta base de datos publica desde 1932 una bibliografía internacional de obras traducidas gracias a la colaboración de distintas instituciones culturales de todo el mundo, pero su utilidad para nuestro estudio es limitada, ya que sufre un relativo retraso en la actualización de la información que recibe de los distintos países. En el caso de Alemania y España, tal y como recoge la propia página web en la como el catálogo de la Biblioteca Nacional de España, que recoge toda la producción editorial española, incluidas las traducciones, así como la base de datos de libros editados en España, gestionada por el Ministerio de Cultura y Deporte.

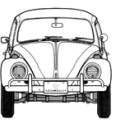

\section{DATOS OBTENIDOS}

En total se comprobó el número de traducciones publicadas al español de 88 autores, de procedencias muy diversas y que como elemento común tienen una obra escrita mayoritariamente en alemán. A continuación se muestran los datos obtenidos en las búsquedas citadas. En la tabla I aparecen los autores analizados con indicación de si tienen alguna obra traducida al castellano.

De un total de 88 autores analizados, se ha obtenido el dato de que solo se han traducido al castellano las obras de 25 ellos, es decir, el $28 \%$ de la producción original analizada. Los autores que sí cuentan con versiones de su obra en español se muestran en la tabla 2. En relación con el año de publicación de las traducciones, hay que apuntar que se ha tenido en cuenta el año de publicación de la primera traducción de cada obra y no sus reediciones.

De esos 25 autores, a in de ellos solo se les ha publicado una única obra en castellano, como es el caso de Saša Stanišić o Feridun Zaimoğlu («der sich selbst als "Kanaken-Houllebecq bezeichnet"», según Mein [2004: 2003]); y hay 6 de los que existen 3 o más obras vertidas al español.

Respecto a las fechas de publicación de las

sección Updates, ya se cuenta con los datos de ambos países correspondientes a los años 2012 y anteriores, pero estos datos están siendo aún procesados. En el caso de Alemania, de hecho, el equipo de Index Translationum ya tiene los datos estadísticos de 20I5; sin embargo, los últimos publicados son los de 2009. En el caso de los datos del mercado español, los últimos recibidos son de 20I2, pero los últimos publicados son de 2008. 


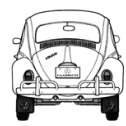

208

\begin{tabular}{|c|c|c|c|c|c|c|c|c|}
\hline & $\mathrm{N}$ & $\mathrm{E}$ & & $\mathrm{N}$ & $\mathrm{E}$ & & $\mathrm{N}$ & $\mathrm{E}$ \\
\hline I & Melinda Nadj Abonji & sí & 30 & Sabrina Janesch & no & 60 & Lore Reimer & no \\
\hline 2 & Ghazi Abdel-Qadir & sí & $3 \mathrm{I}$ & Veena Kade-Luthra & no & 6I & Zé Do Rock & no \\
\hline 3 & Salim Alafenisch & sí & 32 & Vera Kamenko & no & 62 & Magdalena Sadlon & no \\
\hline 4 & Zsuzsa Bánk & sí & 33 & Wladimir Kaminer & sí & 63 & Rafik Schami & sí \\
\hline 5 & Artur Becker & no & 34 & Yadé Kara & no & 64 & Saliha Scheinhardt & no \\
\hline 6 & Habib Bektaş & no & 35 & Adel Karasholi & no & 65 & Dieter Schlesak & sí \\
\hline 7 & Franco Biondi & no & 36 & Abbas Khider & no & 66 & Paul Schuster & no \\
\hline 8 & Marica Bodrožić & no & 37 & Esther Kinsky & no & 67 & Zafer Şenocak & no \\
\hline 9 & Fawzi Boubia & no & 38 & Giorgos Krommidas & no & 68 & Adam Soboczynski & sí \\
\hline IO & Irena Brežná & no & 39 & Kemal Kurt & no & 69 & Saša Stanišić & sí \\
\hline II & Ann Cotten & no & 40 & Tatjana Kuschtewskaja & no & 70 & Michael Stavarič & no \\
\hline I2 & Güney Dal & no & $4 \mathrm{I}$ & Gabriel Laub & no & $7 \mathrm{I}$ & Franco Supino & no \\
\hline I3 & György Dalos & no & 42 & Nicol Ljubić & no & 72 & Suleman Taufiq & no \\
\hline I4 & Eleni Delidimitriou- & & 43 & Wendelin Mangold & no & 73 & Yoko Tawada & sí \\
\hline & Tsakmaki & no & 44 & Hisako Matsubara & sí & 74 & Alev Tekinay & no \\
\hline I5 & Şinasi Dikmen & no & 45 & Libuše Moníková & sí & 75 & Eleni Torossi & no \\
\hline I6 & Dimitré Dinev & no & 46 & Terézia Mora & sí & 76 & Ilija Trojanow & sí \\
\hline I7 & Osman Engin & no & 47 & Jusuf Naoum & no & 77 & Galsan Tschinag & sí \\
\hline I8 & Vaios Fassoulas & no & 48 & Aziz Nesin & no & 78 & Nellja Veremej & no \\
\hline I9 & Sherko Fatah & sí & 49 & Margareth Obexer & no & 79 & Vladimir Vertlib & no \\
\hline 20 & Ota Filip & sí & 50 & Chima Oji & no & 80 & Aglaja Veteranyi & sí \\
\hline $2 \mathrm{I}$ & Cătălin Dorian Florescu & sí & $5^{\mathrm{I}}$ & Emine Sevgi Özdamar & sí & $8 \mathrm{I}$ & Christina Viragh & no \\
\hline 22 & Lia Frank & no & $5^{2}$ & Selim Özdoğan & no & 82 & Nelly Wacker & no \\
\hline 23 & Dante Andrea Franzetti & no & 53 & Kerim Pamuk & no & 83 & Johann Warkentin & no \\
\hline 24 & Zsuzsanna Gahse & no & 54 & Erica Pedretti & no & 84 & Waldemar Weber & no \\
\hline 25 & Marjana Gaponenko & no & 55 & Katja Petrowskaja & sí & 85 & Natascha Wodin & no \\
\hline 26 & Kostas Giannakakos & no & 56 & Nora Pfeffer & no & 86 & Yusuf Yesilöz & no \\
\hline 27 & Olga Grjasnowa & sí & 57 & Afik Pirinçci & sí & 87 & Rumjana Zacharieva & no \\
\hline 28 & Nino Haratischwili & sí & $5^{8}$ & Julya Rabinowich & no & 88 & Feridum Zaimoğlu & sí \\
\hline 29 & Viktor Heinz & no & 59 & Ilma Rakusa & no & & & \\
\hline
\end{tabular}

$\mathrm{N}$ : nombre del autor. E: obra traducida al español

traducciones, las más antiguas son las de la obra de Ota Filip, de los años I970 y 1972: El café de la calle del cementerio y Un loco para cada ciudad. Las más recientes se han publicado en 2016 y 2018: En pleno verano, de Zsuzsa Bánk y Sofía o el origen de todas las historias, del sirio-alemán Rafik Schami, ambas en 2or6, y La octava vida: para Brilka, de Nino Haratischwili y Memorias de una osa polar, de Yoko Tawada en 2018. ${ }^{\text {Io }}$ Les sigue una obra de la misma autora japonesa con

ro También se publicó en 2018 El hombre superfluo, de Trojanow, una obra que no es ficción, sino un ensayo humanista y analítico sobre nuestro tiempo. No obstante, se contempla la inclusión de Trojanow en este estudio por escribir, sobre todo, literatura de ficción. Como ya se ha dicho, se excluye a quienes publican mayoritariamente trabajos de no ficción. 
Tabla 2. Autores con obra(s) traducida(s) al español y fecha de publicación de las traducciones

\begin{tabular}{|c|c|c|c|c|c|c|c|}
\hline & Autor & $\mathrm{N}$ & $\mathrm{F}$ & & Autor & $\mathrm{N}$ & $\mathrm{F}$ \\
\hline I & Melinda Nadj Abonji & I & $20 I I$ & I5 & Katja Petrowskaja & I & 2015 \\
\hline 2 & Ghazi Abdel-Qadir & 5 & I996, I999, 2000 y 2002(2) & I6 & Afik Pirinçci & I & 1995 \\
\hline 3 & Salim Alafenisch & 2 & I992 y I995 & I7 & Rafik Schami & II & I989, I990, I994 (2), \\
\hline 4 & Zsuzsa Bánk & 2 & 2004 y 2016 & & & & I995, 1996, 2000, 2005, \\
\hline 5 & Sherko Fatah & I & 2003 & & & & 2008,2009 y 2016 \\
\hline 6 & Ota Filip & 2 & I970 y I972 & I8 & Dieter Schlesak & I & 2OII \\
\hline 7 & Cătălin Dorian Florescu & 2 & 2007 y 2010 & I9 & Adam Soboczynski & 2 & 2011 y 2013 \\
\hline 8 & Olga Grjasnowa & I & 2013 & 20 & Saša Stanišić & I & 2008 \\
\hline 9 & Nino Haratischwili & I & 2018 & $2 \mathrm{I}$ & Yoko Tawada & 2 & 2016 y 2018 \\
\hline IO & Wladimir Kaminer & 3 & 2003,2004 y 2010 & 22 & Ilija Trojanow & 4 & I998, 2008, 2012 \\
\hline II & Hisako Matsubara & 2 & I983 y I985 & & & & y 2018 \\
\hline I2 2 & Libuše Moníková & 4 & I989, I993, I994 у I997 & 23 & Galsan Tschinag & 2 & 1995 y 2007 \\
\hline I3 & Terézia Mora & I & 2006 & 24 & Aglaja Veteranyi & I & 2002 \\
\hline I4 & Emine Sevgi Özdamar & 4 & I994, I996, 2000 y 2005 & 25 & Feridum Zaimoğlu & I & 2008 \\
\hline
\end{tabular}

$\mathrm{N}$ : número de obras traducidas. F: fecha de publicación de las traducciones

Tabla 3. Autores más traducidos.

\begin{tabular}{lllll}
\hline & Autor & Procedencia & N & Años de publicación de las traducciones \\
\hline I & Rafik Schami & Siria & II & I989, I990, I994 (2), I995, I996, 2000, 2005, 2008, 2009 y 2016 \\
2 & Ghazi Abdel-Qadir & Palestina & 5 & I996, I999, 2000 y 2002 (2) \\
3 & Libuše Moníková & Repúb.Checa & 4 & I989, I993, I994 y 1997 \\
4 & Emine Sevgi Özdamar & Turquía & 4 & I994, I996, 2000 y 2005 \\
5 & Ilija Trojanow & Bulgaria & 4 & I998, 2008, 20I2 y 2018 \\
6 & Wladimir Kaminer & Rusia & 3 & 2003, 2004 y 2010 \\
\hline
\end{tabular}

$\mathrm{N}$ : número de obras traducidas

Escamigera (2016) y, ya en 2015, Tal vez Esther, de Katja Petrowskaja. De todas las traducciones tenidas en cuenta para este estudio (un total de 58), 23 se editaron en el siglo pasado y 35 en el presente, lo que nos hace ver con ligero optimismo la evolución de estas traducciones en los próximos años. En los últimos diez años, es decir, desde 2007, se han publicado 22 de estas traducciones, otro indicador que nos mueve al optimismo.
Pero ¿cuáles son las obras que más se traducen al español? Hay que decir en este punto que los autores más traducidos son también los autores que más recientemente han visto publicada su obra en castellano (tabla 3 ).

La primera posición la ocupa, con una notable diferencia respecto a los demás, el sirioalemán Rafik Schami, con once títulos vertidos al castellano. Instalado en Alemania desde los 25 años, en 1971, comenzó a publicar en alemán ya 
en 1978 (Andere Märchen), principalmente cuentos y relatos infantiles (Das Schaf im Wolfspelz, Das letzte Wort der Wanderratte, Der Kameltreiber von Heidelberg, Das ist kein Papagei, etc.) pero también novelas dirigidas a un público infantil (Eine Hand voller Sterne, Das Geheimnis des Kalligraphen) e incluso adulto (Die Frau, die ibren Mann auf dem Flohmarkt verkaufte, oder wie ich zum Erzäbler wurde y Sophia oder Der Anfang aller Geschichten). Su obra ha cosechado siempre un gran éxito de crítica y público, ha sido traducida a una treintena de idiomas y es conocida por sus resonancias orientales (damascenas ante todo) y exóticas, y por ser fiel reflejo de la multiculturalidad de la que hace gala tanto en su vida privada como en sus apariciones públicas y en todos sus textos. Al castellano se han vertido varios de sus cuentos infantiles y novelas juveniles (Un puñado de estrellas [1989], Narradores de la noche [I990], El honesto mentiroso [1994], ¡No es un papagayo! [1994], La sonrisa de la luna [1995], Viaje entre la noche y la mañana [1996], Las mil y una noches de Goethe [2000], Cómo curé a papá de su miedo a los extraños [2005], El lado oscuro del amor [2008], El secreto del calígrafo [2009]) y su novela más reciente, Sofía o el origen de todas las historias (2016).

$\mathrm{E} 1$ siguiente autor en número de traducciones también dirige su obra, al igual que Schami, a los lectores más jóvenes y llama la atención que sea asimismo de procedencia árabe: el palestino Ghazi Abdel-Qadir, con cinco obras traducidas al castellano (además de la obra colectiva de relatos El sentido de la vida [Salamandra, 2005]): El camello de hojalata (1996), El aguador: la historia de Abú Ali, su asno Chamchum y todos los demás (1999), Cabello de trigo (2000), Las piedras hablan (2002) y El regalo de la abuela Sara (2002). En sus cuentos, como en los de Schami, las resonancias orientales envuelven los textos en un halo de exotismo y otredad muy atractivo para los pequeños lectores.
A Abdel-Qadir le siguen, con cuatro publicaciones en castellano, Libuše Moníková, Emine Sevgi Özdamar e Ilija Trojanow. Moníková, de origen checo y afincada en Alemania desde I971, despuntó en aquel país sobre todo gracias a su novela Die Fassade (I987), vertida al español al año de su aparición en lengua original (La fachada, I989). Este éxito provocó que se tradujera posteriormente una obra previa, Pavana para una infanta difunta (I993), y hasta dos producciones posteriores (Hielos a la deriva [1994] y Noche transfigurada [1997]). Su temprano fallecimiento en 1998 a la edad de 52 años interrumpió irremisiblemente su producción, un hecho que afecta a la recepción y distribución de su obra en otros idiomas. Distinta es tanto la temática como el tipo de producción de Özdamar, que va desde el teatro a los relatos cortos pasando por la novela. Al igual que en el caso de la autora checa, la traducción al español de la novela que definitivamente la encumbró en Alemania (La vida es un caravasar [1994]), con notable éxito de crítica y ventas en nuestro país, supuso la posterior edición en castellano de una obra anterior (La lengua de mi madre [I996]), y el interés no decreció posteriormente, como demuestran las traducciones El puente del Cuerno de Oro (2000) y Extrañas estrellas (2005).

Por su parte, las obras de Trojanow y Kaminer están claramente impregnadas del fenómeno migratorio y de la propia biografía de cada uno de ellos, aunque con enfoques bien distintos. Trojanow, de origen búlgaro, emigró a Kenia y residió en París, Alemania y Mumbai; los ecos de sus viajes y experiencias tienen reflejo directo en su vasta producción, como autor pero también como editor, si bien logró el éxito de crítica y público más con su segunda que con su primera novela: se trata de Der Weltensammler, que recibió el afamado premio de la Feria del Libro de Leipzig en 2006 y que se editó en español en 
2008 como El coleccionista de mundos (ya en 1996 había publicado El mundo es grande y la salvación acecha por todas partes, traducida tan solo dos años después al castellano), ambas publicadas después de un buen número de relatos de viajes y antologías. Después llegaría DesHielo (20I2). A Trojanow se le considera más cercano a André Malraux, Arthur Koestler o Pablo Neruda que a Mimitré Dinev o Vladimir Vertlieb (cf. Hübner, 2008: 94), y de él se llega a decir que es parte «der neuen postkolonialen, transkulturellen, hybriden Mischkultur und -literatur, wie sie von Autoren wie Salman Rushdie, Hanif Kureishi u.a. vertreten wird» (ibidem).

Muy distinta es la producción del ruso Kaminer, personaje popularmente conocido y reconocido no solo por su producción literaria, sino también, y sobre todo, por su exposición pública (cf. Spazzarini, 2008 y Mehnert, 20I4). De tintes claramente cómicos, los relatos de Kaminer hacen de la migración el eje sobre el que giran los relatos y las travesuras lingüísticas del autor. A pesar de la dificultad añadida que suponen para la traducción tanto los juegos de palabras como las realidades interculturales que se ven reflejadas en sus trabajos, la colección de relatos La disco rusa (2003) vio la luz en español, a la que siguieron la novela Música militar (2004) y la más reciente Yo no soy berlinés: una guía para turistas vagos (2010). Su obra se ha enmarcado dentro de la llamada «cultura del entretenimiento", a la vez que ejerce una mordaz crítica hacia el sistema de valores de la sociedad actual (Spazzarini, 2008: 106).

Respecto a los traductores de estas obras, tal y como se observa en el Anexo I, es raro que un mismo traductor se ocupe de toda la obra de uno de estos autores (únicamente destacan en este sentido Miguel Sáenz, traductor único de la obra de Emine Sevgi Özdamar al castellano, y Helga Pawlowsky, que se hizo cargo de las cua- tro traducciones al castellano de Moníková). Se observa una falta de continuidad no solo en las labores de traducción, también las propias licencias de traducción cambian de sello editorial con cierta frecuencia: así, cada una de las cinco obras de Abdel-Qadir editadas en castellano ha sido traducida por un traductor distinto y en distintas editoriales, y ello en un lapso de tiempo relativamente corto (desde 1996, año en que Alfaguara publica El camello de hojalata, en traducción de Rosa Pilar Blanco, hasta 2002, con la traducción de M.J. Larriba de El regalo de la abuela Sara para El barco de vapor, propiedad de SM). En cuanto a la selección editorial, nótese, por ejemplo, que la obra de Schami la editan en España Alfaguara, Siruela, SM, Muchnik, RqueR y Salamandra; o el caso de Wladimir Kaminer, con tres traducciones publicadas en tres sellos distintos, sin olvidar el citado caso de Abdel-Qadir.

\section{Discusión}

De los datos expuestos cabe extraer algunas conclusiones que en modo alguno pretenden ser ni representativas ni concluyentes, sino que pueden dar pie a estudios futuros que indaguen en este asunto o continúen allí donde nosotros no hemos llegado.

De los 88 autores analizados, solo 25 han visto su obra vertida al castellano en el período de tiempo estudiado (1950-20I8). No parece una cifra muy alta, pero tampoco lo son los números globales de las traducciones del alemán al castellano en términos generales: en 2017 se tradujeron del alemán al español i68 obras de creación literaria. No obstante, en líneas anteriores hemos apuntado hacia el optimismo que se puede desprender del aumento de traducciones observado en los últimos años: de los autores aquí analizados, solamente en lo que va de siglo han visto la luz en España más obras que en los 50 años precedentes (el 60\% del total analizado). 
Que últimamente se traduzca más que en los años precedentes no es un dato sorprendente en sí mismo, habida cuenta de los cambios producidos en el mercado editorial global en el siglo xx. Quizá deberíamos pensar más bien en los estudios de mercado que realizan los sellos editoriales para garantizar un mínimo de ventas. No en vano, los dos autores más traducidos al castellano son quienes dirigen su obra al público infantil y juvenil: es bien conocido que este tipo de literatura es la que más volumen de negocio genera en términos generales y tres de cada diez libros de literatura infantil y juvenil publicados en España son traducciones, como recoge el último análisis publicado en Panorámica de la edición española de libros 20I7: «E1 subsector con más traducciones fue el de libros infantiles y juveniles $(54,7 \%)$, seguido por el de creación literaria $(22,8 \%)$; en literatura infantil y juvenil y en libros de creación literaria la lengua más traducida ha sido el inglés» (Ministerio de Cultura y Deporte, 2018: 28). De hecho, la mayor parte de las licencias de traducción vendidas al extranjero por editoriales alemanas corresponde al grupo de literatura infantil y juvenil. Respecto a las licencias de traducción vendidas a España por Alemania, de las $4 \mathrm{I} 2$ vendidas en 2015 , 137 pertenecían a este tipo de literatura. ${ }^{\text {II }}$

La reflexión que cabe hacer sobre la selección editorial gira en torno al previsible éxito editorial que pueden cosechar en español obras que han tenido una buena acogida en Alemania, con independencia del origen o ecos exóticos de sus autores y textos: no solo los autores más traducidos son los que publican para el público infantil y juvenil; hay además que tener en cuenta que un buen número de los autores aquí tratados

\footnotetext{
II Datos extraídos del Goethe Institut: https:// www.goethe.de/ins/es/es/kul/sup/lit/bid.html (consulta: I3-XI-2OI8).
}

solo encuentran una de sus obras traducidas al castellano, por lo general la obra que les encumbró inicialmente: autores como Sherko Fatah, Saša Stanišić, Feridum Zaimoğlu, Olga Grjasnowa, Katha Petrowskaja o Nino Haratischwili, por citar solo unos ejemplos, son creadores reconocidos en Alemania y que han cosechado grandes éxitos y obtenido premios (como Sherko Fatah, que ganó el premio al mejor debú literario en alemán en 200I y el Adelbert von Chamisso en 2015; Grjasnowa obtuvo el citado Förderpreis de la Fundación Bosch ese mismo año; Petrowskaja fue galardonada con el premio Ingeborg Bachmann en 20I4, etc.). Verter sus obras al castellano (aquella que supuso un punto de inflexión en sus carreras) es una garantía de éxito, y por lo tanto podemos coincidir con la citada Cecilia Dreymüller, quien, en un intercambio de correo a propósito de la publicación de este trabajo, explica que las traducciones que hoy en día se publican en nuestro país de la literatura proveniente del espacio germanófono son de tinte exclusivamente comercial y que es la maquinaria editorial la que lanza a los nuevos autores y los promueve

porque se acoplan exactamente a su acomodaticia línea actual de entretenimiento políticamente correcto y culturalmente tuneado: infaliblemente ofrecen una mezcla de personal multiétnico, escenarios globales, ritmo trepidante y contenidos enriquecidos artificialmente por conflictos bélicos internacionales. La soltura y destreza con las que están escritos compiten sólo con su previsibilidad. Es una literatura profesional de cabo a rabo que no experimenta, no apela a la inteligencia, no despierta la conciencia, no conmueve. Es estéril y se vende muy bien. ${ }^{\text {I2 }}$

I2 Comunicación personal con Cecilia Dreymüller a propósito de este trabajo. Texto reproducido con permiso de la autora. 
Ciertamente, los nuevos autores de esta literatura intercultural son lanzados por las grandes editoriales como Suhrkamp o Fischer y entran en un circuito de promociones propio de los grandes sellos, lo que incluye también la venta de las licencias de traducción a otras lenguas.

\section{A MODO DE CONCLUSIÓN}

Por lo expuesto hasta el momento podría decirse que este tipo de literatura tiene una notable presencia en el mercado editorial en lengua alemana (Dreymüller, 20I7) y que existe un creciente interés —al menos así parecen mostrarlo estas estadísticas, en modo alguno concluyentes- por estas obras en España, si bien no se detecta un criterio claro de selección y posterior publicación de este tipo de literatura por parte de las editoriales españolas.

Mención aparte merecen las traducciones a otra de las lenguas oficiales de España, el catalán: muchas de las obras aquí incluidas, y otras tantas no vertidas al castellano, se han traducido a esta lengua, especialmente desde el inicio del siglo XXI (solo en 2017 se tradujeron del alemán al catalán 92 obras, 38 de las cuales eran obras de creación literaria, ${ }^{\mathrm{r} 3}$ un dato que contrasta con las 168 obras literarias traducidas del alemán al castellano en ese mismo año, habida cuenta de que el catalán cuenta con ro millones de hablantes $\left.{ }^{\mathrm{I}}\right)$. Sin duda se observa tanto un notable interés por este tipo de lite-

I3 Datos extraídos de la consulta personal realizada para este trabajo al Observatorio de la Lectura y el Libro. Cabe destacar también que Cataluña fue la invitada de honor en la Feria del Libro de Frankfurt en el año 2007, un foro en que se establecen cooperaciones editoriales a largo plazo y se gestiona buena parte de las licencias de traducción de editoriales alemanas.

I4 Dato extraído del Institut Ramon Llull: https:// www.llull.cat/espanyol/cultura/llengua_catala.cfm (consulta: I3-XII-20I8). ratura en Cataluña y regiones en que el catalán funciona como lengua vehicular como un ingente esfuerzo del mercado editorial catalán en este sentido, aspectos ambos que merecerían un estudio adicional complementario al que aquí se aporta.

En todo caso, la pregunta que quizá sea más pertinente plantear ahora es si se debe considerar para el mercado editorial español este tipo de literatura intercultural o de migración escrita originalmente en alemán como un ente en sí mismo que deba ser tratado como un conjunto homogéneo de obras de temática común o que de algún modo compartan una serie de características que las sitúen dentro de un mismo compartimento estanco. La migración es hoy en día, más que un fenómeno esporádico, un signo de nuestro tiempo y, quizá por ello, coincidiendo en gran medida con los autores antes citados, no debamos tender a etiquetar nuevas corrientes literarias o formas de escribir por el mero hecho de la procedencia mixta de sus autores o por sus orígenes exóticos. En este sentido resulta paradigmático el caso de la celebérrima revista británica Granta, que publica un listado con los mejores jóvenes narradores británicos cada diez años y que se ha convertido en todo un referente literario (no en vano, en la primera lista Granta [1983] ya aparecía Kazuo Ishiguro, quien obtendría el Nobel en 2017). En su última edición, de 20I3, sorprende que muchos de los novelistas enumerados no hayan nacido en suelo británico o que sean descendientes de emigrantes, y hay quien apunta a que su inclusión no solo trae nuevas historias a la literatura occidental, sino nuevas elecciones formales y estilísticas que pueden subvertir las convenciones de la novela europea, como sucede con la obra de Nadifa Mohamed Black Mamba Boy (La mamba negra, en traducción de Montse Triviño para Emecé) o con la produc-

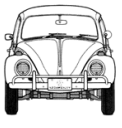

213 
ción de Helen Oyeyemi. ${ }^{15}$ Como curiosidad, sirva apuntar que, de esos 20 novelistas, I6 tienen su obra vertida al castellano (y de estos, 5 cuentan con versiones en catalán de sus obras). Podríamos incluso hablar de un mercado editorial global, cada vez menos circunscrito a localismos y que refleja más bien una época, la nuestra, de movimientos migratorios que han dejado de ser una excepción para convertirse en lo habitual.

Ya Dreymüller apuntaba que los criterios editoriales para publicar literatura alemana en español son verdaderamente comerciales, pues no se busca «tanto la excelencia artística o la relevancia sociopolítica de un determinado título, como su resonancia publicitaria, encaminada a optimizar el número de ejemplares vendidos» (Dreymüller, 2008: 350); de ahí que el lector español se forme una idea de la actualidad literaria alemana con productos «deslavazados y banales» (ibidem). Si tomamos, por ejemplo, la exitosa obra de Rafik Schami, prolífico escritor de origen sirio emigrado a Alemania cuyo trabajo se dirige fundamentalmente al público infantil y juvenil —y que además es, de todos los autores analizados, el más traducido al castellano-; o la del también prolífico y muy leído tanto en Alemania como en España Abdel-Qadir, ¿no debería más bien hablarse del interés que en España despiertan obras que ya han conocido el éxito en su país de publicación

I5 Vid. «Granta list of top young novelists is femaledominated and international", The Guardian, 15 de abril de 20I3. Disponible en: <https://www.theguardian.com/ books/2013/apr/15/granta-list-novelists-female-international> [consulta: IO-III-20I8]. Algo similar ocurre con la última lista Granta de los Estados Unidos (de 20I7), muy diversa también en cuanto al origen de los autores seleccionados (vid. «The age of anxiety: what does Granta's best young authors list say about America?», The Guardian, 26 de abril de 20I7. Disponible en: <https://www.theguardian. $\mathrm{com} /$ books/20I7/apr/26/granta-pick-best-young-americanauthors-great-american-novel> [consulta: I3-XI-2018]). original, en lugar del deseo del público lector en castellano por conocer la literatura de migración escrita en alemán?

Otro aspecto que merece ser tenido en cuenta, y que no por ser obvio debe dejar de mencionarse, es la pertinencia de traducir ciertas obras al español por el hecho de estar tremendamente focalizadas en el fenómeno migratorio en Alemania y no en otro país, por mucho que se aborden temas de relevancia internacional y comunes a toda migración humana. Sirvan como ejemplo las obras del turco Şinasi Dikmen, con títulos tan elocuentes como Integrier dich, Opa! o Hurra, ich lebe in Deutschland. Satiren, o el caso del trabajo de Viktor Heinz Der eine spricht, der andere schwätzt, der dritte babbelt. Einiges über die Mundarten der Deutschen aus Russland (2008). El público lector al que se dirigen estas obras, u otras de similar naturaleza de tantos otros escritores migrantes, no deja de ser un público o bien alemán o, cuando menos, muy conocedor de la realidad alemana, sus usos y costumbres, sus bondades y sus defectos, y siempre desde el prisma del emigrado, del ajeno a esa nueva cultura. Estas obras reflejan una realidad que, si bien puede ser extrapolable a los emigrantes de otros orígenes que se establecen en nuevos países, se refiere exclusivamente las dificultades y peculiaridades de la emigración a Alemania. Por no hablar de obras que incluso podríamos tildar de prácticamente intraducibles, como es el caso de la obra de la menonita rusa Lore Reimer, cuyo trabajo más conocido se titula Du kaunst miene Sproak vestohne (2009) escrito en gran medida en el alemán que hablan los menonitas rusos-, si bien este es un aspecto que no ha impedido ni que se viertan a otros idiomas películas con temáticas de marcado carácter cultural ni que estas tengan éxito en otros países (Almanya, Bienvenidos al norte, por citar solo dos ejemplos), un hecho que se debe, 
a nuestro entender, tanto a la universalidad de los temas abordados en ellas como, y no podemos dejar de apuntarlo, al buen hacer de los traductores.
Son preguntas, en fin, que quedan en el aire y a las que estudios futuros o el mero transcurrir del tiempo habrán de dar respuesta.

RECIBIDO EN ABRIL DE 2018 ACEPTADO EN OCTUBRE DE 2018 VERSIÓN FINAL DE ENERO DE $20 I 9$

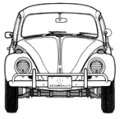

215

\section{ANEXO I}

Tabla de los autores analizados que cuentan con traducciones al castellano, con indicación de las obras traducidas y sus traductores

\begin{tabular}{|c|c|c|c|}
\hline Autor/a & Obra original & Título en castellano (año, editorial) & Traductor/a \\
\hline Melinda Nadj Abonji & Tauben fliegen auf & $\begin{array}{l}\text { Las palomas emprenden el vuelo } \\
\text { (20II, El Aleph) }\end{array}$ & Alfonso López Alloza \\
\hline \multirow[t]{7}{*}{ Ghazi Abdel-Qadir } & Das Blechkamel & El camello de hojalata (i996, Alfaguara) & Rosa Pilar Blanco \\
\hline & Der Wasserträger & El aguador: la historia de Abú Ali, su asno & Carlos Fortea Gil \\
\hline & & Chamchum y todos los demás (I999, Edebé) & \\
\hline & Weizenhaar & Cabello de trigo (200o, Edelvives) & Soraya Hernán-Gómez \\
\hline & Die sprechenden Steine & Las piedras que hablan (2002, Edelvives) & Amalia Bermejo \\
\hline & Das Geschenk & El regalo de la abuela Sara & M. J. Larriba \\
\hline & von Großmutter Sara & (2002, El barco de vapor) & \\
\hline \multirow[t]{2}{*}{ Salim Alafenisch } & Der Weibrauch Händler & El mercader de incienso (1992, Siruela) & Violeta Pérez Gil \\
\hline & Amira, Prinzessin der Wüste & Amira, princesa del desierto (1995, Siruela) & Rosa Pilar Blanco \\
\hline \multirow[t]{2}{*}{ Zsuzsa Bánk } & Der Schwimmer & El nadador (2004, Acantilado) & Berta Vías Mahou \\
\hline & Heissester Sommer & En pleno verano (2016, Acantilado) & Marina Bornas Montaña \\
\hline Sherko Fatah & Im Grenzland & Tierra de frontera $\left(2 \mathrm{OO}_{3}\right.$, Siruela $)$ & María Falcón Quintana \\
\hline \multirow[t]{2}{*}{ Ota Filip } & $\begin{array}{l}\text { Das Café an der Straße } \\
\text { zum Friedhof }\end{array}$ & $\begin{array}{l}\text { El café de la calle del cementerio } \\
\text { (I970, Plaza \& Janés) }\end{array}$ & Martín Ezcurdia \\
\hline & Ein Narr für jede Stadt & Un loco para cada ciudad (I972, Plaza \& Janés) & José Manuel Pomares \\
\hline \multirow{2}{*}{ Cătălin Dorian Florescu } & Der blinde Masseur & El masajista ciego (2007, Lengua de Trapo) & Isabel Hernández \\
\hline & Zaira & Zaira (2ого, Maeva) & Ana Cosutic \\
\hline Olga Grjasnowa & $\begin{array}{l}\text { Der Russe ist einer, } \\
\text { der Birken liebt }\end{array}$ & $\begin{array}{l}\text { A los rusos les gustan los abedules } \\
\text { (2013, Edicions Còmplices) }\end{array}$ & Lidia Álvarez Grifoll \\
\hline Nino Haratischwili & Das achte Leben (Für Brilka) & La octava vida: para Brilka (2018, Alfaguara) & Carlos Fortea Gil \\
\hline \multirow[t]{3}{*}{ Wladimir Kaminer } & Russendisko & La disco rusa (2003, Debolsillo) & Luis Miralles de Imperial \\
\hline & Militärmusik & Música militar (2004, RBA) & Macarena González \\
\hline & Ich bin kein Berliner & $\begin{array}{l}\text { Yo no soy berlinés: una guía para turistas vagos } \\
\text { (2oro, Serv. Publi. Univ. Rey Juan Carlos) }\end{array}$ & 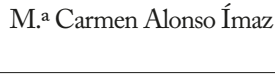 \\
\hline \multirow[t]{2}{*}{ Hisako Matsubara } & Brokatrausch & Samurai (1983, Círculo de Lectores) & Luis Ogg \\
\hline & Abendkranich & Pájaros del crepúsculo (1985, Tusquets) & Manuel Sáenz de Heredia \\
\hline \multirow[t]{5}{*}{ Libuše Moníková } & Die Fassade & La fachada (1989, Muchnik) & Helga Pawlowsky \\
\hline & Pavane für eine & Pavana para una infanta difunta & Helga Pawlowsky \\
\hline & verstorbene Infantin & (I993, Anaya \& Mario Muchnik) & \\
\hline & Treibeis & Hielos a la deriva (1994, Anaya \& M.Muchnik) & Helga Pawlowsky \\
\hline & Verklärte Nacht & Noche transfigurada (I997, Anaya \&M.Muchnik) & Helga Pawlowsky \\
\hline
\end{tabular}




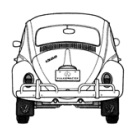

216
Autor/a

Terézia Mora

Emine Sevgi Özdamar
Obra original

Alle Tage

hat zwei Türen, aus einer kam ich

rein, aus der anderen ging ich raus

Mutterzunge

La lengua de mi madre (1996, Alfaguara)

Título en castellano (año, editor)

Traductor/a

Die Brücke vom goldenen Horn El puente del Cuerno de Oro (2000, Alfaguara)Miguel Sáenz Seltsame Sterne starren zur Erde Extrañas estrellas (2005, Alfaguara)

\begin{tabular}{ll}
\hline Katja Petrowskaja & Vielleicht Esther \\
\hline Afik Pirinçi & Felidae \\
\hline Rafik Schami & Eine Hand voller Sterne \\
& Erzähler der Nacht \\
& Der ehrliche Lügner \\
& Das ist kein Papagei! \\
& Bobo und Susu \\
& Reise zwischen Nacht und Morgen \\
& Der geheime Bericht über \\
& den Dichter Goethe \\
& Wie ich Papa die Angst \\
& \\
& Die dunkle Seite der Liebe \\
& Das Geheimnis des Kalligraphen \\
& Shopia oder der Anfang \\
& aller Geschichten
\end{tabular}

Dieter Schlesak Capesius,

der Auschwitzapotheker

Adam Soboczynski Die schonende Abwehr verliebter Frauen

Glänzende Zeiten

\begin{tabular}{ll}
\hline Saša Stanišić & Wie der Soldat \\
& das Grammofon repariert \\
\hline Yoko Tawada & Das Bad \\
& Etüden im Schnee
\end{tabular}

Ilija Trojanow

Die Welt ist gross

und Rettung lauert überall

Der Weltensammler

Eis Tau

Der überflüssige Mensch

\begin{tabular}{ll}
\hline Galsan Tschinag & $\begin{array}{l}\text { Der blaue Himmel } \\
\text { Dojnaa }\end{array}$ \\
\hline Aglaja Veteranyi & $\begin{array}{l}\text { Warum das Kind } \\
\text { in der Polenta kocht }\end{array}$ \\
\hline Feridum Zaimoğlu & Leyla
\end{tabular}

Tal vez Esther (2015, Adriana Hidalgo)
Felidae (I995, Urano)
Un puñado de estrellas (1989, Alfaguara)
Narradores de la noche (1990, Siruela)
El honesto mentiroso (I994, Siruela)
¡No es un papagayo! (I994, SM)
La sonrisa de la luna (I995, SM)

Miguel Sáenz

Nicolás Gelormini
Irene Dun de Leal

J.M.Rodríguez Clemente

Antón Dieterich

Antón Dieterich

Marinella Terzi

Rosanna Terzi

Carlos Fortea Gil

Las mil y una noches de Goethe (2000, Muchnik) Marta Pascual

Cómo curé a papá de su miedo a los extraños

Rocío González Lovelle (2005, RqueR)

El lado oscuro del amor (2008, Salamandra)

Carlos Fortea Gil

Carlos Fortea Gil

Susana Andrés

Sofía o El origen de todas las historias (2or6, Salamandra)

Capesius, el farmace

Christian Martí-Menzel (2oIr, Seix Barral)

El arte de no decir la verdad (20II, Anagrama) Francesc Rovira

El libro de los vicios (2013, Anagrama)

Francesc Rovira

Cómo el soldado repara el gramófono Richard Gross
(2008, Alfaguara)

Escamigera: cuento extranjero (2016, Franz D. L.) Fernando Lasarte Memorias de una osa polar (20I8, Anagrama) Belén Santana El mundo es grande y la salvación acecha Joan Parra por todas partes (1998, Tusquets)

El coleccionista de mundos (2008, Tusquets) Rosa Pilar Blanco DesHielo (2012, Rayo Verde)

El hombre superfluo (2018, Plataforma Editorial S. L.)

Cielo azul (1995, Siruela) Dojnaa (2007, Txalaparta)

Rosa Pilar Blanco José Aníbal Campos

\begin{tabular}{ll}
$\begin{array}{l}\text { Por qué se cuece el niño en la polenta } \\
\text { (2012, Lengua de Trapo) }\end{array}$ & Soaquín Polo Marco Schläfli \\
\hline Leyla (2008, 45I Editores) & Valentín Ugarte
\end{tabular}




\section{REFERENCIAS BIBLIOGRÁFICAS}

Ackermann, Irmgard (2008), «Die Osterweiterung in der deutschsprachigen "Migrantenliteratur“ vor und nach der Wende», en Michaela BürgerKoftis (ed.), Eine Sprache - viele Horizonte... Die Osterweiterung der deutschsprachigen Literatur. Porträts einer neuen europäischen Generation, Viena: Praesens Verlag, I3-22.

Amodeo, Inmaculada, Heidrum Hörner y Christiane Kiemle (eds.) (2009): Literatur obne Grenzen. Interkulturelle Gegenwartsliteratur in Deutschland - Porträts und Positionen, Sulzbach/ Taunus: Ulrike Helmer Verlag.

Ardanuy Soldevilla, Isabel (2018): Informe de feria. Buchmesse / Feria del Libro. Fráncfort 20I8, Düsseldorf: ICEX España Exportación e Inversiones.

Bнавна, Homi K. (1994): The Location of Culture, Londres y Nueva York: Routledge.

Bozzi, Paola (2005): Der fremde Blick: Zum Werk Herta Müllers, Würzburg: Königshausen \& Neumann.

Bürger-Koftis, Michaela (ed.) (2008): Eine Sprache - viele Horizonte... Die Osterweiterung der deutschsprachigen Literatur. Porträts einer neuen europäischen Generation, Viena: Praesens Verlag.

Burdorf, Dieter, Christoph Fasbender y Burkhard Moennighoff (eds.) (2007): Metzler Lexikon Literatur. Begriffe und Definitionen, Stuttgart: Metzler Verlag.

Chiellino, C. (ed.) (2000): Interkulturelle Literatur in Deutschland - Ein Handbuch, Stuttgart: Metzler Verlag 2000.

Cornejo, Renata, Sławomir Piontek, Izabela SellMER y Sandra VLAsta (eds.) (20I4): Wie viele Sprachen spricht die Literatur? Deutschsprachige Gegenwartsliteratur aus Mittel- und Osteuropa, Viena: Prasens Verlag.

Cuéllar Lázaro, M. Carmen (2000): Dobletes de traducción y traductologia: las traducciones al castellano en España de la literatura contemporánea en lengua alemana (1945-1990), Valladolid: Universidad de Valladolid.

Cuéllar Lázaro, M. Carmen (2005): «La literatura contemporánea en lengua alemana en España: 45 años de traducciones», Estudios Filológicos Alemanes, 9, 3I3-324.

Dreymüller, Cecilia (2004): «Anmerkungen zur Präsenz der deutschsprachigen Literatur in
Spanien», en W. Bader y J. I. Olmos (eds.), Die deutsch-spanischen Kulturbeziehungen im europäischen Kontext, Fráncfort: Vervuert, 6I-66.

Dreymüller, Cecilia (2008): Incisiones. Panorama critico de la narrativa en lengua alemana desde 1945, Barcelona: Círculo de Lectores/Galaxia Gutenberg.

Dreymüller, Cecilia (20I7): «Las novelas de la era Merkel», El Pais, Babelia. 23 de septiembre.

Durzak, Manfred y Nilüfer Kuruyazic (eds.) (2004), Die andere Deutsche Literatur. Istanbuler Vorträge, Würzburg: Königshausen und Neumann.

Esselborn, Karl (2004): «Deutschsprachige Minderheitenliteraturen als Gegenstand einer kulturwissenschaftlichen orientierten "interkulturellen Literaturwissenschaft" ", en Manfred Durzak y Nilüfer Kuruyazic (eds.), Die andere Deutsche Literatur. Istanbuler Vorträge, Würzburg: Königshausen und Neumann, II-23.

Feld, Natalia (20IO): «Von der Migrationsliteratur zu translationswissenschaftlichen Entwürfen», en Nina A. Frieß, Inna Ganschow, Irina Gradiari y Marion Rutz (eds.), Texturen - Identitäten Theorien: Ergebnisse des Arbeitstreffen des Jungen Forums Slavistische Literaturwissenschaft in Trier 20I0, Potsdam: Universitätsverlag Potsdam, 443$45^{8}$.

Fortea, Carlos (2009): Dos cambios de siglo. Ensayos sobre literatura alemana traducida. Berna: Peter Lang.

Hernández, Isabel (2013): «¿Un amor imposible? Acerca de la traducción de literatura alemana en España durante el siglo Xx», Estudios de Traducción, vol. 3, 315-327.

Hoffmeister, Gerhard (1976): Spanien und Deutschland. Geschichte und Dokumentation der literarischen Beziehungen, Berlín: Erich Schmidt.

HüBNER, Karl (2008): «Fließen Kulturen ineinander? Über Ilija Trojanow», en Michaela BürgerKoftis, M. (ed.), Eine Sprache — viele Horizonte... Die Osterweiterung der deutschsprachigen Literatur. Porträts einer neuen europäischen Generation, Viena: Praesens Verlag, 83-95.

Kamm, Martina, Bettina Spoerri, Daniel Rothen büHLER y Gianni D'Amato (eds.) (20Io): Diskurse in die Weite. Kosmopolitische Räume in den Literaturen der Schweiz, Zürich: Seismo Verlag.

Kreuzer, Helmut (I984): «Gastarbeiter-Literatur,

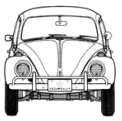




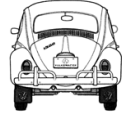

218
Ausländer-Literatur, Migranten-Literatur?», Zeitschrift für Literaturwissenschaft und Linguistik, 56, 7-II.

Mecklenburg, Norbert (2004): «Eingrenzung, Ausgrenzung, Grenzüberschreitung, Grundprobleme deutscher Literatur von Minderheiten», en Manfred Durzak y Nilüfer Kuruyazic (eds.), Die andere Deutsche Literatur. Istanbuler Vorträge, Würzburg: Königshausen und Neumann, 23-30.

Mehnert, E. (20I4): «Wladimir Kaminer - der gute Russe aus Berlin», en Renata Cornejo, Slawomir Piontek, Izabela Sellmer y Sandra Vlasta (eds.), Wie viele Sprachen spricht die Literatur? Deutschsprachige Gegenwartsliteratur aus Mittel- und Osteuropa, Viena: Prasens Verlag, Io8-I24.

Mein, Georg (2004), «Die Migration entlässt ihre Kinder. Sprachliche Entgrenzungen als Identitätskonzept», en Clemmens Kammle y Torsten Pflugmacher (eds.), Deutschsprachige Gegenwartsliteratur seit 1989. Zwischenbilanzen - Analysen - Vermittlungsperspektiven, Heidelberg: Synchron, 20I-2I7.

Ministerio de Cultura (2010): Libro blanco de la traducción editorial en España. Madrid: Secretaría General Técnica. Subdirección General de Publicaciones, Información y Documentación y tt ace traductores. <http://www.cedro.org/docs/lecturas/libro_blanco_acett_2oIo.pdf?Status=Master > [consulta: 5-X-20I7].

Ministerio de Cultura y Deporte (2018): Panorámica de la edición española de libros 20I7. Madrid: Secretaría General Técnica. Subdirección General de Documentos y Publicaciones. <https://sede. educacion.gob.es/publiventa/panoramica-de-laedicion-de-libros-2016/edicion/2106IC> [consulta: IO-XI-20I8].

Pazarkaya,Yüksel (1984): «Türkiye, Mutterland - Almanya, Bitterland... Das Phänomen der türkischen Migration als Thema der Literatur», Zeitschrift für Literaturwissenschaft und Literatur, 56, IOI-I24.

Pereyra, Soledad (2016): «Ante los retos del multiculturalismo (o la literatura transnacional en alemán hoy)», Moderna språk, I, 83-ıoo.

Rosell, Anna (2007): "Manifestaciones poéticas de la identidad en la literatura de autores neoalemanes: ¿a qué llamamos literatura intercultural?», Revista de Filología Alemana, vol. I5, I27-I37.

Ruiz, Ana (2005), «Literatura intercultural frente a canon nacional en Alemania: pautas para la resolución de un conflicto», Revista de Filología Alemana, vol. I3, 27-48.

SAAlbach, Mario (I995): «Missverständliches Verstehen oder verstehendes Missverständnis? Zur Rezeption zeitgenössischer deutschsprachiger Literatur in Spanien», en Margit Raders y M. Luisa Schilling (eds.), Deutsch-Spanische Literatur- und Kulturbeziehungen. Rezeptionsgeschichtel Relaciones hispano-alemanas en la literatura y la cultura. Historia de la recepción, Madrid: Ediciones del Orto, 257-266.

SÁEnz, Miguel (I989): «Geschichte einer unmöglichen Liebe. Die deutsche Literatur in Spanien seit I945", en H. L. Arnhold (ed.), Ansichten und Auskünfte zur deutschen Literatur nach 1945, Múnich: Text + Kritik Sonderband, I68-I78.

Santana López, Belén, Críspulo Travieso RodríGuez y Manuel DE LA CRuz Recio (20I7): «La visibilidad del traductor en catálogos y repertorios bibliográficos españoles (I970-20I0): posibilidades y estrategias de análisis», en Maria da Graça Simões y Maria Manuel Borges (coords.): Tendências atuais e perspetivas futuras em organização do conhecimento. Atas do III Congresso ISKO Espanha-Portugal, Coimbra: Universidade de Coimbra, I06I-1070.

Spazzarini, Serena (2008): «Wladimir Kaminer: Kultautor zwischen Literatur, Musik, Theater, Radio und Journalismus», en Michaela BürgerKoftis (ed.), Eine Sprache - viele Horizonte... Die Osterweiterung der deutschsprachigen Literatur. Porträts einer neuen europäischen Generation, Viena: Praesens Verlag, 97-106.

Spoerri, Bettina (2008): «Mobil Grenzen, neue Sprachräume. Das Phänomen der Osterweiterung in der deutschsprachigen Literatur der Schweiz», en M. Bürger-Koftis (ed.), Eine Sprache - viele Horizonte... Die Osterweiterung der deutschsprachigen Literatur. Porträts einer neuen europäischen Generation, Viena: Praesens Verlag, I99-2II.

Spoerri, Bettina (20IO): «Deterritorialisierungsstrategien in der transnationalen Literatur der Schweiz - ein aktueller Paradigmenwechsel», en Martina Kamm, Bettina Spoerri, Daniel Rothenbühler y Gianni D'Amato (eds.), Diskurse in die Weite. Kosmopolitische Räume in den Literaturen der Schweiz, Zürich: Seismo Verlag, 3I-52.

Thore, P. (2004): «wer bist du bier in dieser stadt, in 
diesem land, in dieser neuen welt». Die Identitätsbalance in der Fremde in ausgewäblten Werken der deutschsprachigen Migrantenliteratur, Uppsala: Uppsala Universitet.

Valero Cuadra, Pino (20io): «Las traducciones al español de literatura intercultural alemana", Cuadernos de Filología Alemana, Anejo III, 30I-309.

Weinberg, Marc (20I4): «Was heißt und zu welchem Ende liest man Migrantenliteratur? Mit Anmerkungen zum Werk Libuše Moníkovás», en R. Cornejo, S. Piontek, I.Sellmer y S. Vlasta (eds.), Wie viele Sprachen spricht die Literatur? Deutschsprachige Gegenwartsliteratur aus Mittelund Osteuropa, Viena: Prasens Verlag, 15-36.

WeINRICH, Harald (I984): "Gastarbeiterliteratur in der Bundesrepublik Deutschland», Zeitschrift für Literaturwissenschaft und Linguistik 56, 12-22.

\section{FUENTES DE CONSULTA}

Base de datos de libros editados en España (http:// www.culturaydeporte.gob.es/cultura-mecd/areascultura/libro/bases-de-datos-del-isbn/base-de-

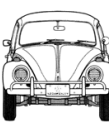
datos-de-libros.html) [consulta: I3-XI-20I8].

Catálogo de la Biblioteca Nacional de España (http://catalogo.bne.es/uhtbin/webcat) [consulta: I3-XI-20I8].

Deutsche Nationalbibliothek (http://www.dnb.de/ DE/Kataloge/kataloge_node.html) [consulta: I3-XI-20I8].

Index Translationum de la UNESCO (http://www. unesco.org/xtrans/) [consulta: I3-XII-2OI7]. 